\title{
Influencing Factors on the Physicochemical Characteristics of Tea Polysaccharides
}

\author{
Ting Hu ${ }^{1,2, *}$, Peng Wu ${ }^{1}$, Jianfeng Zhan ${ }^{1}$, Weixin Wang ${ }^{1}$, Junfeng Shen ${ }^{1}$, Chi-Tang Ho ${ }^{3}$ and Shiming Li ${ }^{1,3, *}$ \\ 1 Hubei Key Laboratory of Economic Forest Germplasm Improvement and Resources Comprehensive \\ Utilization, Huanggang Normal University, Huanggang 438000, China; wupeng201412@163.com (P.W.); \\ zhanjianfeng2010@163.com (J.Z.); wangweixin1009@aliyun.com (W.W.); jfshen@hgnu.edu.cn (J.S.) \\ 2 Fisheries Research Institute of Fujian, Xiamen 361013, China \\ 3 Department of Food Science, Rutgers University, New Brunswick, NJ 08901, USA; ctho@sebs.rutgers.edu \\ * Correspondence: 13419602772@163.com (T.H.); shiming@rutgers.edu (S.L.)
}

Citation: Hu, T.; Wu, P.; Zhan, J.; Wang, W.; Shen, J.; Ho, C.-T.; Li, S. Influencing Factors on the

Physicochemical Characteristics of Tea Polysaccharides. Molecules 2021 26, 3457. https://doi.org/10.3390/ molecules 26113457

Academic Editors: Lesław Juszczak and Janusz Kapusniak

Received: 5 May 2021

Accepted: 5 June 2021

Published: 7 June 2021

Publisher's Note: MDPI stays neutral with regard to jurisdictional claims in published maps and institutional affiliations.

Copyright: (c) 2021 by the authors. Licensee MDPI, Basel, Switzerland. This article is an open access article distributed under the terms and conditions of the Creative Commons Attribution (CC BY) license (https:// creativecommons.org/licenses/by/ $4.0 /)$.

\begin{abstract}
Tea polysaccharides (TPSs) are one of the main bioactive constituents of tea with various biological activities such as hypoglycemic effect, antioxidant, antitumor, and immunomodulatory. The bioactivities of TPSs are directly associated with their structures such as chemical composition, molecular weight, glycosidic linkages, and conformation among others. To study the relationship between the structures of TPSs and their bioactivities, it is essential to elucidate the structure of TPSs, particularly the fine structures. Due to the vast variation nature of monosaccharide units and their connections, the structure of TPSs is extremely complex, which is also affected by several major factors including tea species, processing technologies of tea and isolation methods of TPSs. As a result of the complexity, there are few studies on their fine structures and chain conformation. In the present review, we aim to provide a detailed summary of the multiple factors influencing the characteristics of TPS chemical structures such as variations of tea species, degree of fermentation, and preparation methods among others as well as their applications. The main aspects of understanding the structural difference of TPSs and influencing factors are to assist the study of the structure and bioactivity relationship and ultimately, to control the production of the targeted TPSs with the most desired biological activity.
\end{abstract}

Keywords: tea polysaccharides (TPSs); chemical structure; tea species; processing technologies; isolation methods

\section{Introduction}

Tea, an important agricultural product made from the fresh leaves and buds of plant Camellia sinensis, is the most consumed functional beverage in the world [1]. It has a long history of dietary and medicinal application, especially in Asian countries-such as China, Japan, India, and Thailand-for more than five thousand years [2]. According to the manufacturing process, tea can be categorized as unfermented green, white, and yellow teas, partly-fermented oolong and raw pu-erh teas, fully fermented black, pu-erh and dark teas, and post-fermented dark tea [3]. The processing methods including withering, rolling, fermentation, post-fermentation, and roasting of tea, and other factors such as cultivars, degree of ripeness, geographical location and agricultural practices will affect the content and structure of active compounds, resulting in the changes of biological activities. Tea possesses multiple biological functions, including antioxidant, hypoglycemic effect, anti-microbial, lowering blood lipids, and anticancer $[1,4,5]$. These biological activities have been attributed to the variety of chemical ingredients of tea, mostly to tea polyphenols such as catechins, theaflavins, thearubigins, theasinensins and other flavonoids, but also polysaccharides, alkaloids (caffeine, theobromine and theophylline), proteins, lipids, and inorganic elements (selenium, iron, manganese, etc.) among others [1,4-6]. 
Other than tea polyphenols, the group of tea polysaccharides (TPSs) is one of the main bioactive constituents of tea and the content varies from approximately $1.5 \%$ to nearly 13\% [7]. Figure 1 illustrates a general structure of TPSs, but is noninclusive due to the complexity of TPS structures. Recently, TPSs have attracted increasing levels of attention due to their various biological activities, including antioxidant [3,8-12], antitumor [13,14], anti-diabetes [12,15-17], antifatigue [18], anticoagulant [19], anti-obesity [20], hypoglycemic [16,21,22], and immunomodulatory activities [23,24]. According to the reports, TPSs contained 2-10 monosaccharides such as glucose (Glc), rhamnose (Rha), arabinose (Ara), mannose (Man), ribose (Rib), xylose (Xyl), galactose (Gal), fucose (Fuc), galacturonic acid (GalA), and glucuronic acid (GluA), and the monosaccharides linked by multiple glycosidic linkages such as $1 \rightarrow 2,1 \rightarrow 3,1 \rightarrow 4,1 \rightarrow 6$, leading to a wide range of molecular weight $\left(\mathrm{M}_{\mathrm{w}}\right)$ distribution (MWD) [4,7]. The molecular structure of a TPS is composed of multiple monosaccharide units. Similar to amino acids in proteins, the composition and linkage of individual monosaccharides have many different ways, resulting in variety of TPSs. Due to the nature of poly-monosaccharide unit composition, multiple sites of connection and chain conformation, the structures of TPSs vary dramatically in molecular weight, chain length and connection type, configuration and others. Hence the composition and connections of monosaccharide units are the defining parameters of TPSs. The molecular weight $\left(\mathrm{M}_{\mathrm{W}}\right)$ of a TPS is determined by the number of single monosaccharide units and the conformation of a TPS is directly associated with the types of monosaccharides and their linking position between two adjacent monosaccharides. Therefore, the components of monosaccharides and their connecting style are the basic foundations of TPSs. Factors affecting the composition and connection of monosaccharides are thereby influencing the structures of TPSs, which in turn influence the biological activities.

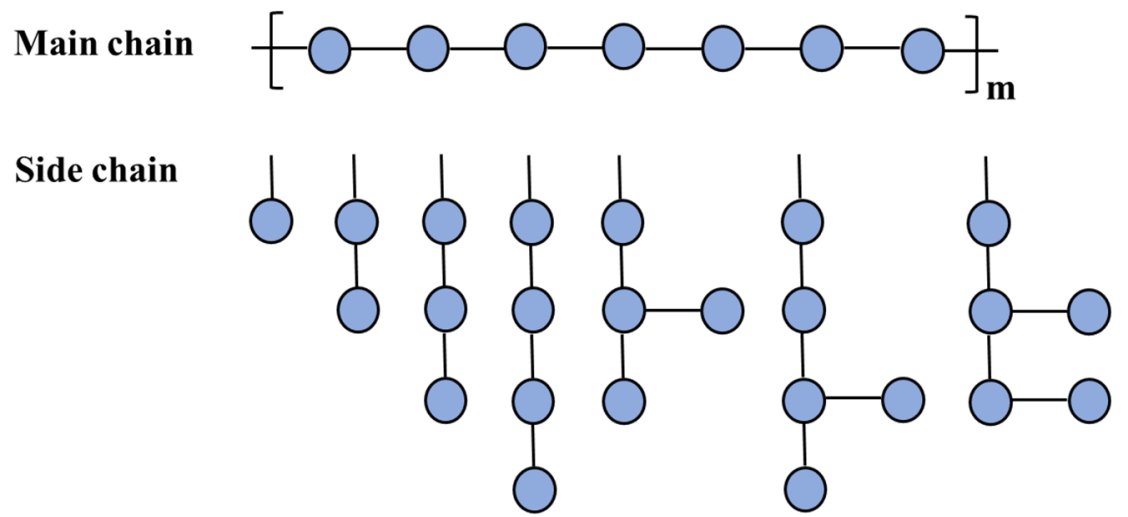

Glc, Gal, Rha, Xyl, Ara, Fuc.

$-1 \rightarrow 2,1 \rightarrow 3,1 \rightarrow 4,1 \rightarrow 6$.

Figure 1. General structure of TPSs.

Therefore, to further study the biological property of TPSs and to effectively correlate the bioactivity and the structure of TPSs, it is also essential to understand and elucidate the fine structure of TPSs and the factors contributing to their variety, particularly the monosaccharide units and their connection. There are multiple factors that can cause the differentiation of monosaccharide composition and linkage, but the main ones are tea species, tea process, and isolation method of TPSs. The aim of this review is to provide a comprehensive summary of structural variety of TPSs and factors affecting the polymorphism of TPS structures, to associate the influential factors, TPS structures and bioactivity, and to enhance the characteristic understanding of TPS structure and to enhance the application of TPSs in the fields of bioactive polysaccharides and functional foods. 


\section{Preparation of TPSs}

A schematic diagram of extraction and purification of TPSs is shown in Figure 2. Different types of teas-including green, white, yellow, oolong, black, and dark teaare obtained by different manufacture processes. Different extraction methods-such as hot water extraction (HWE), boiling water extraction (BWE), ultrasound-assisted extraction (UAE), microwave-assisted extraction (MAE), enzyme extraction (EE), and supercritical liquid extraction (SLE) - are used to extract TPSs from tea leaves, seeds, and flowers $[9,16,25,26]$. After decolorization, deproteinization and dialysis of the extracted solution, alcohol precipitation is used to obtain the crude TPSs. The crude TPSs are further purified by ultrafiltration or column chromatography filled with separating materials including DEAE-cellulose, Anion exchange resin D315, DEAE Sepharose, Sephadex G100 gel, Superdex-200, Sephacryl S-300, and others [9,17,23,27-29]. The purified TPSs are usually lyophilized for readiness in characterization and biological activities study.

Different extraction methods

Hot water extraction

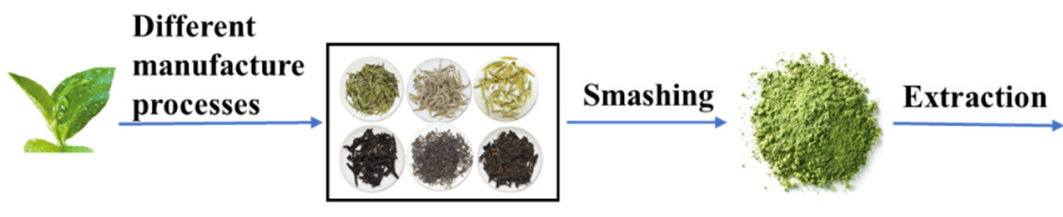

Boiled water extraction

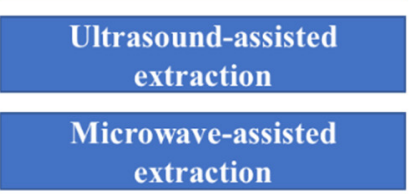

Enzyme extraction

Supercritical liquid extraction

Column chromatography

DEAE-cellulose column

Anion exchange resin D315 column

Freeze drying

\section{DEAE Sepharose fast flow gel} column

Sephadex G-100 gel column

Superdex-200 column

Sephacryl S-300 column

Figure 2. A schematic diagram of extraction and purification of TPSs. 
The traditional water extraction (WE) method is widely used because of its simple operation and low cost. However, due to its long extraction time and low yield, various assisted extraction methods such as UAE, MAE, and EE are developed to improve the yield of TPS. UAE and MAE have the advantages of simple, rapid, energy-saving and high efficiency, but they will have a certain impact on the bioactivity of TPS. The reaction conditions of EE are mild, which will not affect the bioactivity of TPS, but the cost is relatively high. In addition, a novel extraction method, SLE has the advantages of low energy consumption, high efficiency, mild, and environmental-friendly, but the equipment is expensive and the extraction time is long.

\section{Physicochemical Characterization of TPSs}

The physicochemical characterization of TPSs includes monosaccharide composition, molecular weight $\left(\mathrm{M}_{\mathrm{W}}\right)$, sequence of monosaccharides, location of glycosidic linkages, degree of branches, configuration, and conformation of the entire molecule. The monosaccharide composition of TPSs is usually analyzed using gas chromatography (GC) and GCmass spectroscopy (GC-MS) after the hydrolysis of glycosidic linkages by trifluoroacetic acid (TFA) and derivatization with acetic anhydride. Gel permeation chromatography (GPC), gel-filtration chromatography (GFC), and/or multiangle laser light-scattering instrument (MLLS) are used to determine the $\mathrm{M}_{\mathrm{w}}$ of TPSs. The chemical structures of TPSs are complex and determined by UV-vis, Fourier transform infrared spectroscopy (FT-IR), GC, GC-MS, 1D and 2D nuclear magnetic resonance spectroscopy (NMR), transmission electron microscopy (TEM), atomic force microscopy (AFM) combined with monosaccharide composition analysis, periodate oxidation, Smith degradation, partial acid hydrolysis, and methylation analysis.

To date, more than 120 TPSs have been extracted and isolated from various types of tea. The main chemical characteristics of TPSs, such as the composition of monosaccharides, average $M_{w}$ and chemical structure, are summarized in Tables 1 and 2. As illustrated in Table 1, TPSs are heteropolysaccharides, consisting of 2-10 monosaccharides which contain Glc, Rha, Ara, Man, Rib, Xyl, Gal, Fuc, GalA, and GluA, with the average $\mathrm{M}_{\mathrm{w}}$ ranged from 1.02 to $4940 \mathrm{kDa}$. There are only several studies about the chemical structure and chain conformation of TPSs, the main monosaccharides are Glc, Gal, Rha, Xyl, Ara, and Fuc and the linkages of main chain are $1 \rightarrow 2,1 \rightarrow 3,1 \rightarrow 4$, and $1 \rightarrow 6$ as shown in Figure 1 . The conformation of TPSs in solution is characterized as sphere-like, random coil, and/or ordered helix-coil shapes $[30,31]$. The differences in monosaccharide composition, average $\mathrm{M}_{\mathrm{w}}$ and chemical structure are closely related with the material, manufacture processes, extraction, and isolation methods of TPSs. 
Table 1. Influencing factors on the monosaccharide composition and molecular weight of tea polysaccharides.

\begin{tabular}{|c|c|c|c|c|c|c|c|c|c|c|c|c|c|c|}
\hline \multirow{2}{*}{ Resource } & \multirow{2}{*}{$\begin{array}{l}\text { Processing Technologies or } \\
\text { Extraction Methods }\end{array}$} & \multirow{2}{*}{ Name } & \multicolumn{10}{|c|}{ Monosaccharide Composition (mol.\% or Mole Ratio) } & \multirow{2}{*}{$\mathrm{M}_{\mathrm{w}} / \mathrm{kDa}$} & \multirow{2}{*}{ References } \\
\hline & & & Glc & Rha & Ara & Man & Rib & Xyl & Gal & Fuc & GalA & GluA & & \\
\hline $\begin{array}{c}\text { Green tea leaves } \\
\text { (Artificially Se-enriched Enshi) }\end{array}$ & \multirow{2}{*}{$\operatorname{HWE}\left(90^{\circ} \mathrm{C}\right)$} & ASe-TPS2 & 1.00 & 1.93 & 7.05 & & & 1.05 & & & 26.12 & & 6.73 & \\
\hline $\begin{array}{c}\text { Green tea leaves } \\
\text { (Naturally Se-enriched Enshi) }\end{array}$ & & NSe-TPS2 & 0.10 & 0.28 & 0.59 & & & & 1.00 & 0.07 & 1.24 & 0.49 & 244.32 & [28] \\
\hline \multirow{3}{*}{$\begin{array}{l}\text { Green tea leaves } \\
\text { (Se-enriched Enshi) }\end{array}$} & \multirow{3}{*}{$\operatorname{HWE}\left(70^{\circ} \mathrm{C}\right)$} & Se-TPS & 0.49 & 0.22 & 0.71 & 0.12 & 0.14 & & 1.00 & 0.03 & 1.39 & 0.13 & 1.3-1020 & \multirow{3}{*}{ [32] } \\
\hline & & Se-TPS1 & 0.47 & 0.21 & 0.58 & & & & 1.00 & 0.07 & 1.75 & 0.17 & 110 & \\
\hline & & Se-TPS2 & 0.10 & 0.28 & 0.59 & & & & 1.00 & 0.07 & 1.24 & 0.49 & 240 & \\
\hline $\begin{array}{c}\text { Green tea } \\
\text { (Se-enriched Ziyang) }\end{array}$ & $\operatorname{HWE}\left(80^{\circ} \mathrm{C}\right)$ & Se-TP & 32.35 & 1.69 & 30.64 & 3.57 & & & 25.81 & & 2.26 & & - & [18] \\
\hline \multirow{4}{*}{$\begin{array}{l}\text { Green tea } \\
\text { (Coarse) }\end{array}$} & WE & WE-CTPS & 29.22 & 4.11 & 9.96 & 4.62 & & 3.46 & 28.05 & 4.14 & 16.43 & & $3.0-2560$ & \multirow{4}{*}{ [16] } \\
\hline & WAE & UAE-CTPS & 36.05 & 2.27 & 9.22 & 4.75 & & 5.38 & 27.54 & 6.72 & 8.07 & & $3.2-3680$ & \\
\hline & MAE & MAE-CTPS & 31.09 & 4.03 & 11.84 & 6.17 & & 3.64 & 27.06 & 6.84 & 9.33 & & $3.1-2500$ & \\
\hline & $\mathrm{EE}$ & EE-CTPS & 44.24 & 5.40 & 8.86 & 4.38 & & 3.15 & 12.32 & 11.78 & 9.87 & & 3.0-3150 & \\
\hline $\begin{array}{l}\text { Green tea } \\
\text { (Low grade) }\end{array}$ & HWE & TPC & 14.10 & 8.74 & 29.04 & 7.11 & & 0.42 & 35.89 & 4.69 & & & $6.62,48.5,455$ & [33] \\
\hline Green tea & BWE & GSP & 7 & 2 & 19 & & & & 7 & & 65 & & - & [35] \\
\hline $\begin{array}{c}\text { Green tea } \\
\text { (Huangshan Maofeng) }\end{array}$ & $\operatorname{HWE}\left(80^{\circ} \mathrm{C}\right)$ & HMTP & 7.4 & 2.3 & 28.9 & 4.9 & 6.1 & 1.1 & 35.0 & & 11.3 & 3.0 & - & [36] \\
\hline \multirow{3}{*}{ Green tea } & \multirow{3}{*}{-} & TF-1 & 1 & & & 3.2 & & 1.4 & & & & & 231.6 & \multirow{3}{*}{ [37] } \\
\hline & & TF-2 & 1 & & & & & 1.7 & & & & & 46.3 & \\
\hline & & TF-3 & 1 & & 0.9 & & & 2.5 & & & & & 7.3 & \\
\hline Green tea & $\mathrm{NaCl}$ solution extraction & ALTPS & 23.8 & 1.6 & 6.9 & 1.0 & 1.7 & 0.6 & 6.6 & & & & - & [38] \\
\hline \multirow{2}{*}{ Green tea } & $\operatorname{HWE}\left(90^{\circ} \mathrm{C}\right)$ & TPC-W & 14.10 & 8.74 & 29.04 & 7.11 & & 0.42 & 35.89 & 4.69 & & & $6.62-4550$ & \multirow{2}{*}{ [39] } \\
\hline & $\mathrm{AE}$ & TPC-A & 6.28 & 13.81 & 36.07 & 4.89 & & 5.24 & 32.27 & 1.43 & & & $4.13-4940$ & \\
\hline Green tea & $\operatorname{HWE}\left(70^{\circ} \mathrm{C}\right)$ & GTPS & 17 & 7.8 & 41.8 & 7.3 & & 7.1 & 18.7 & & & & $9.2-251.5$ & [8] \\
\hline Green tea & HWE $\left(65^{\circ} \mathrm{C}\right)$ with EE & ATPS-2 & & 0.68 & & & & & 1.00 & & 1.58 & & 4.43 & [29] \\
\hline \multirow{3}{*}{ Green tea } & \multirow{3}{*}{$\operatorname{HWE}\left(75^{\circ} \mathrm{C}\right)$} & Shufeng & 18.70 & 3.15 & 33.90 & 2.45 & & 3.36 & 38.44 & & & & 127 & \multirow{3}{*}{ [40] } \\
\hline & & Longjin D & 17.17 & 3.38 & 32.42 & 2.83 & & 2.80 & 41.41 & & & & 106 & \\
\hline & & Jialaoshan & 16.36 & 3.53 & 32.31 & 3.14 & & 2.67 & 42.97 & & & & 121 & \\
\hline Green tea & $\operatorname{HWE}\left(75^{\circ} \mathrm{C}\right)$ & TPF & 1.01 & 1 & 18.86 & 5.73 & & 2.47 & 18.54 & 1.01 & & & - & [41] \\
\hline Green tea & EE & TPS & 43.27 & & 6.49 & & & 2.60 & 41.11 & 6.53 & & & 110 & [42] \\
\hline
\end{tabular}


Table 1. Cont.

\begin{tabular}{|c|c|c|c|c|c|c|c|c|c|c|c|c|c|c|}
\hline \multirow{2}{*}{ Resource } & \multirow{2}{*}{$\begin{array}{l}\text { Processing Technologies or } \\
\text { Extraction Methods }\end{array}$} & \multirow{2}{*}{ Name } & \multicolumn{10}{|c|}{ Monosaccharide Composition (mol.\% or Mole Ratio) } & \multirow{2}{*}{$\mathbf{M}_{\mathrm{w}} / \mathbf{k D a}$} & \multirow{2}{*}{ References } \\
\hline & & & Glc & Rha & Ara & Man & Rib & Xyl & Gal & Fuc & GalA & GluA & & \\
\hline Green tea leaves & BWE & $7 \mathrm{WA}$ & & & 1.0 & & & & 0.96 & & & & 71 & [17] \\
\hline \multirow{3}{*}{$\begin{array}{l}\text { Green tea leaves } \\
\text { (Coarse) }\end{array}$} & Untreated & TPSU & 1.00 & 0.88 & 1.19 & 0.34 & & & 1.00 & & & & $1-330$ & \multirow{3}{*}{ [43] } \\
\hline & Extrusion treatment & TPSE4 & 1.00 & 0.12 & 0.93 & 0.13 & & & 0.62 & & & & $15-330$ & \\
\hline & Extrusion treatment & TPSE12 & 1.00 & 0.20 & 1.11 & 0.18 & & & 0.63 & & & & $4-405$ & \\
\hline \multirow{3}{*}{ Green tea leaves } & Freeze-drying of TPS & TPS-F & 2.82 & 1.0 & 2.77 & 0.45 & 0.58 & 3.12 & 0.14 & & 3.88 & 0.26 & $3.3-952$ & \multirow{3}{*}{ [44] } \\
\hline & Vacuum-drying of TPS & TPS-V & 5.96 & 1.0 & 2.62 & 0.51 & 0.47 & 1.94 & 0.16 & & 3.0 & 0.20 & $3.4-910$ & \\
\hline & Microwave-vacuum drying of TPS & TPS-M & 1.30 & 1.0 & 1.90 & 0.40 & 0.29 & 1.72 & 0.15 & & 1.66 & 0.16 & $3.5-915$ & \\
\hline \multirow{4}{*}{ Green tea leaves } & \multirow{4}{*}{$\operatorname{HWE}\left(60^{\circ} \mathrm{C}\right)$} & TPS-1 & 13.6 & & 39.4 & 10.2 & 0.3 & 0.5 & 31.0 & 1.3 & 2.1 & 0.9 & 20.8 & \multirow{4}{*}{ [19] } \\
\hline & & TPS-2 & 1.0 & 4.1 & 36.4 & 0.9 & & 2.3 & 43.1 & 0.1 & 6.9 & 5.2 & 24.2 & \\
\hline & & TPS-3 & 7.0 & 3.5 & 13.0 & 0.6 & 0.1 & 0.2 & 22.1 & 0.1 & 49.1 & 3.9 & 250.6 & \\
\hline & & TPS-4 & 4.0 & 3.1 & 7.7 & 0.8 & 15.4 & 0.2 & 12.8 & 0.2 & 51.2 & 2.5 & $4.1,689.1$ & \\
\hline \multirow{3}{*}{ Green tea leaves } & HWE & HWE-TLPS & 1.00 & 4.82 & 0.22 & 0.48 & & 0.21 & 2.93 & & 2.06 & 0.22 & $1.17-413$ & \multirow{3}{*}[45]{} \\
\hline & BWE & BWE-TLPS & 1.00 & 0.50 & 1.04 & 0.22 & & 0.06 & 1.38 & & 1.48 & 0.09 & $1.04-458$ & \\
\hline & $\mathrm{EE}$ & EE-TLPS & 1.00 & 1.09 & 1.80 & & & & 2.27 & & 2.36 & 0.12 & $1.02-487$ & \\
\hline $\begin{array}{l}\text { Green tea leaves } \\
\text { (Xihu Longjing) }\end{array}$ & \multirow{3}{*}{$\operatorname{HWE}\left(90^{\circ} \mathrm{C}\right)$} & XTPS & 5.52 & 9.50 & 8.79 & 3.52 & & 1.24 & 13.17 & & & 11.60 & $1.26-810$ & \multirow{3}{*}{ [11] } \\
\hline $\begin{array}{l}\text { Green tea leaves } \\
\text { (Chawentianxia) }\end{array}$ & & CTPS & 11.06 & 8.73 & 11.95 & 3.81 & & 1.17 & 16.53 & & & 15.06 & $12-805$ & \\
\hline $\begin{array}{l}\text { Green tea leaves } \\
\text { (Huizhoulvcha) }\end{array}$ & & HTPS & 7.28 & 9.48 & 23.06 & 3.75 & & 0.96 & 30.68 & & & 18.36 & $1.2-771$ & \\
\hline \multirow{5}{*}{$\begin{array}{c}\text { Green tea leaves } \\
\text { (Chinese tea Zhongcha 108) }\end{array}$} & \multirow{5}{*}{ Hydrothermal extraction } & $\mathrm{F}_{0}$ & 7.5 & 33.8 & & & & 2.1 & 13.9 & & 1.4 & 41.3 & 51.85 & \multirow{5}{*}{ [5] } \\
\hline & & $\mathrm{F}_{0.1}$ & 22.8 & 46.8 & & & & 3.9 & 26.5 & & & & 40.00 & \\
\hline & & $\mathrm{F}_{0.2}$ & 38.3 & 39.7 & & & & & 22.0 & & & & 32.72 & \\
\hline & & $\mathrm{F}_{0.3}$ & 44.7 & 36.4 & & & & & 18.9 & & & & 25.27 & \\
\hline & & $\mathrm{F}_{0.4}$ & 45.9 & 35.8 & & & & & 18.3 & & & & 18.38 & \\
\hline White tea leaves & - & WTPS & 2.2 & 1.1 & 4.2 & 4.5 & & & 1 & & & & 29 & {$[46]$} \\
\hline \multirow{4}{*}{ Green tea flowers } & \multirow{4}{*}{$\operatorname{HWE}\left(90^{\circ} \mathrm{C}\right)$} & TFPS & 11.54 & 10.17 & 49.52 & 2.68 & & 1.49 & 22.04 & 2.58 & & & - & \multirow{4}{*}{ [47] } \\
\hline & & TFPS-1 & 45.39 & & 14.84 & 6.87 & & 12.16 & 18.08 & 2.64 & & & - & \\
\hline & & TFPS-2 & & 11.19 & 55.16 & & & & 33.65 & & & & - & \\
\hline & & TFPS-3 & & 20.95 & 53.34 & & & & 25.71 & & & & - & \\
\hline
\end{tabular}


Table 1. Cont.

\begin{tabular}{|c|c|c|c|c|c|c|c|c|c|c|c|c|c|c|}
\hline \multirow{2}{*}{ Resource } & \multirow{2}{*}{$\begin{array}{l}\text { Processing Technologies or } \\
\text { Extraction Methods }\end{array}$} & \multirow{2}{*}{ Name } & \multicolumn{10}{|c|}{ Monosaccharide Composition (mol.\% or Mole Ratio) } & \multirow{2}{*}{$\mathbf{M}_{\mathrm{w}} / \mathbf{k D a}$} & \multirow{2}{*}{ References } \\
\hline & & & Glc & Rha & Ara & Man & Rib & $\mathrm{Xyl}$ & Gal & Fuc & GalA & GluA & & \\
\hline \multirow{2}{*}{ Green tea flowers } & \multirow{2}{*}{$\operatorname{HWE}\left(80^{\circ} \mathrm{C}\right)$} & TFPS-1 & 1.0 & 0.81 & & & & 1.2 & 0.98 & & & & - & \multirow{2}{*}{ [9] } \\
\hline & & TFPS-2 & 1.0 & 2.3 & 2.3 & & & 0.76 & & & & & 10.1 & \\
\hline Green tea flowers & $\operatorname{HWE}\left(90^{\circ} \mathrm{C}\right)$ & TFPS1 & 1.3 & 1.0 & 2.9 & 0.5 & & & 3.3 & & & & 500 & [48] \\
\hline \multirow{3}{*}{ Green tea flowers } & HWE & HWE-TFPS & 1.00 & 0.36 & 1.19 & 0.23 & & 0.16 & 2.09 & & 0.25 & 0.12 & $1.06-483$ & \multirow{3}{*}[45]{} \\
\hline & BWE & BWE-TFPS & 1.00 & 0.80 & 2.06 & 0.25 & & 0.20 & 2.47 & & 2.20 & 0.13 & $1.06-508$ & \\
\hline & EE & EE-TFPS & 1.00 & 1.33 & 2.90 & 0.21 & & 0.24 & 3.20 & & 2.10 & 0.12 & $1.18-465$ & \\
\hline Green tea seeds & Na-citric acid buffer extraction & TSPS & 1.95 & 0.35 & 0.95 & & & 0.15 & 1.00 & & 0.23 & 0.07 & $3.66-961$ & [10] \\
\hline \multirow{3}{*}{ Green tea seeds } & \multirow{3}{*}{$\begin{array}{l}\text { Extracted with Na-citric acid buffer, } \\
\text { enzyme and hot water in sequence }\end{array}$} & NTSPS & 12.44 & & 1.16 & & & & 1 & & & & 4588 & \multirow{3}{*}{ [49] } \\
\hline & & ATSPS-1 & 0.03 & 0.51 & 0.78 & 0.07 & & 0.09 & 1 & 0.1 & & 0.06 & 500 & \\
\hline & & ATSPS-2 & 23.45 & & & & 0.76 & 0.43 & 1 & & & & 100 & \\
\hline \multirow{4}{*}{ Oolong tea } & Ultrafiltration with $\mathrm{M}_{\mathrm{w}}>80 \mathrm{kDa}$ & OTPS1 & 7.90 & 5.50 & 7.31 & 5.78 & 9.43 & 10.32 & 13.11 & 11.85 & & & - & \multirow{4}{*}[27]{} \\
\hline & Ultrafiltration with $\mathrm{M}_{\mathrm{w}} 30-80 \mathrm{kDa}$ & OTPS2 & 17.13 & 5.39 & 6.90 & 10.90 & 6.90 & 8.43 & 27.32 & 8.20 & & & - & \\
\hline & Ultrafiltration with $\mathrm{M}_{\mathrm{w}} 10-30 \mathrm{kDa}$ & OTPS3 & 35.94 & 6.56 & 5.22 & 8.39 & 7.01 & 8.98 & 13.35 & 5.29 & & & - & \\
\hline & Ultrafiltration with $\mathrm{M}_{\mathrm{w}}<10 \mathrm{kDa}$ & OTPS4 & 27.86 & 6.13 & 4.99 & 4.16 & 11.79 & 7.39 & 3.65 & 7.35 & & & - & \\
\hline $\begin{array}{c}\text { Oolong tea } \\
\text { (Fenghuangdancong) }\end{array}$ & \multirow[t]{2}{*}{$\operatorname{HWE}\left(70^{\circ} \mathrm{C}\right)$} & FTPS & 14.44 & 10.83 & 25.69 & 6.97 & & 2.39 & 35.85 & 3.83 & & & 14,930 & \multirow[t]{2}{*}[50]{} \\
\hline $\begin{array}{c}\text { Oolong tea } \\
\text { (Dahongpao) }\end{array}$ & & DTPS & 22.59 & 10.31 & 22.93 & 5.21 & & 0.28 & 33.59 & 5.09 & & & $42,110,2640$ & \\
\hline Oolong tea & $\operatorname{HWE}\left(70^{\circ} \mathrm{C}\right)$ & OTPS & 21.9 & 16.2 & 43.7 & & & & 18.0 & & & & $5.3-100.9$ & {$[8]$} \\
\hline $\begin{array}{c}\text { Oolong tea } \\
\text { (Anxi Tieguanyin) }\end{array}$ & $\operatorname{HWE}\left(90^{\circ} \mathrm{C}\right)$ & TTPS & 12.74 & 7.41 & 13.78 & 5.7 & & 1.37 & 20.16 & & & 15.49 & $1.2-762$ & [11] \\
\hline \multirow{2}{*}{ Oolong tea } & \multirow{2}{*}{$\operatorname{HWE}\left(75^{\circ} \mathrm{C}\right)$} & Fenghuangdanzong & 14.38 & 3.65 & 31.70 & 2.60 & & 2.79 & 44.87 & & & & 107 & \multirow{2}{*}{ [40] } \\
\hline & & Tieguanyin & 10.18 & 5.77 & 32.56 & 1.22 & & 3.81 & 46.47 & & & & 95 & \\
\hline Black tea & BWE & BSP & 16 & 3 & & & & & 16 & & 35 & & - & {$[35]$} \\
\hline Black tea & $\operatorname{HWE}\left(70^{\circ} \mathrm{C}\right)$ & BTPS & 29.4 & 14.4 & 36.4 & & & & 19.7 & & & & $3.8-32.7$ & {$[8]$} \\
\hline $\begin{array}{c}\text { Dark tea } \\
\text { (Chinese Liubao) }\end{array}$ & $\operatorname{HWE}\left(70^{\circ} \mathrm{C}\right)$ & CLTPS & 0.32 & & 3.36 & 3.84 & & 2.08 & 1.92 & 0.16 & & & $467,11.4$ & [51] \\
\hline \multirow{3}{*}{ Puerh tea } & Aging time of 1 year & PTPS-1 & 16.52 & 5.34 & 21.86 & 21.59 & & 4.04 & 26.93 & 3.64 & & & 2700 & \multirow{3}{*}[12,52]{} \\
\hline & Aging time of 3 years & PTPS-2 & 10.23 & 6.82 & 26.22 & 13.83 & & 0.35 & 39.34 & 3.21 & & & $631-1930$ & \\
\hline & Aging time of 5 years & PTPS-3 & 6.08 & 15.98 & 20.84 & 15.29 & & 0.15 & 40.33 & 1.68 & & & $1160-3900$ & \\
\hline
\end{tabular}


Table 1. Cont.

\begin{tabular}{|c|c|c|c|c|c|c|c|c|c|c|c|c|c|c|}
\hline \multirow{2}{*}{ Resource } & \multirow{2}{*}{$\begin{array}{l}\text { Processing Technologies or } \\
\text { Extraction Methods }\end{array}$} & \multirow{2}{*}{ Name } & \multicolumn{10}{|c|}{ Monosaccharide Composition (mol.\% or Mole Ratio) } & \multirow{2}{*}{$\mathrm{M}_{\mathrm{w}} / \mathrm{kDa}$} & \multirow{2}{*}{ Reference } \\
\hline & & & Glc & Rha & Ara & Man & Rib & Xyl & Gal & Fuc & GalA & GluA & & \\
\hline $\begin{array}{c}\text { Brick tea } \\
\text { (Fuzhuan) }\end{array}$ & $\operatorname{HWE}\left(80^{\circ} \mathrm{C}\right)$ & FBTPS-3 & & 15.50 & 13.90 & 8.70 & & & 19.70 & & 42.20 & & 741 & [53] \\
\hline
\end{tabular}

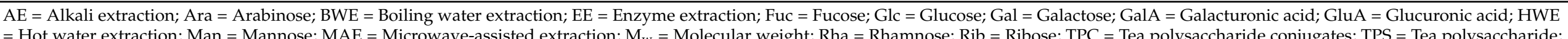

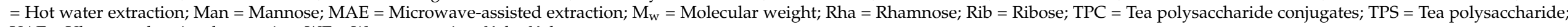

$\mathrm{UAE}=$ Ultrasound-assisted extraction; $\mathrm{WE}=$ Water extraction; $\mathrm{Xyl}=$ Xylose .

Table 2. Influencing factors on chemical structures of tea polysaccharides.

\begin{tabular}{|c|c|c|c|c|c|c|}
\hline Resource & Name & Isolation Methods & \multicolumn{3}{|c|}{ Structural Characterization } & References \\
\hline $\begin{array}{c}\text { Green tea leaves } \\
\text { (Artificial Se-enriched Enshi) }\end{array}$ & ASe-TPS2 & \multirow[t]{2}{*}{$\begin{array}{l}\text { HWE }\left(90^{\circ} \mathrm{C}\right) \rightarrow \text { Ethanol precipitation } \\
(60 \%) \rightarrow \text { Deproteinization } \rightarrow \text { Dialysis } \rightarrow \text { DEAE } \\
\text { Sepharose fast flow gel column }\end{array}$} & 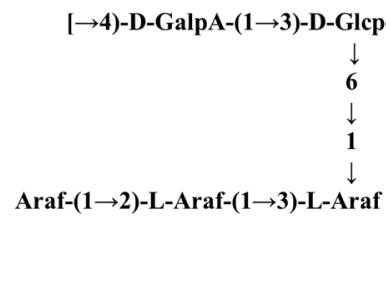 & 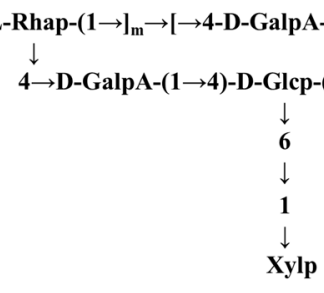 & $\begin{array}{l} \\
\\
\text {-Rhap-1-D-Xylp } \\
\downarrow \\
4 \\
\downarrow \\
1 \\
\downarrow \\
\text { Xylp }\end{array}$ & \multirow[t]{2}{*}{ [28] } \\
\hline $\begin{array}{c}\text { Green tea leaves } \\
\text { (Natural Se-enriched Enshi) }\end{array}$ & NSe-TPS2 & & $\begin{array}{r}{[\rightarrow 4)-D-G a l p A} \\
(\text { Galp, Glcp)-(1 } \rightarrow 2)-L-R h a p-(1 \rightarrow 4\end{array}$ & $\begin{aligned} \text { L-Rhap- }(1 \rightarrow 4)-D-G l c p-(1 \rightarrow]_{\mathrm{m}} \\
\quad \downarrow \\
4 \\
\downarrow \\
\mathrm{p} \rightarrow 1 \\
\rightarrow \text { L-Araf-( }(2 \rightarrow 3)-D-G a l p\end{aligned}$ & 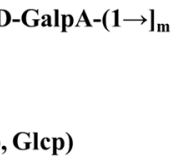 & \\
\hline
\end{tabular}

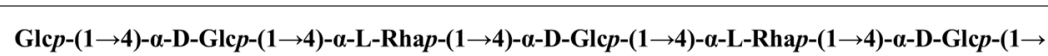

Green tea (Zhongcha 108) $\quad \mathrm{F}_{0.3} \quad \begin{gathered}\text { WE } \\ \left(120^{\circ} \mathrm{C}\right) \rightarrow \underset{\text { Dialysis } \rightarrow \text { Deproteinization } \rightarrow \text { DEAE-52 }}{\text { column }}\end{gathered}$

$\begin{array}{cc}5 & 2 \\ & \downarrow \alpha \\ 1 & \\ \text { D-Gal } p \\ 6 \\ \\ \\ 1 \alpha \\ 1 \\ \text { D-Gal } p\end{array}$

\begin{tabular}{|c|c|c|c|c|}
\hline Green tea & GTPS & \multirow{4}{*}{$\begin{array}{c}\operatorname{HWE}\left(100^{\circ} \mathrm{C}\right) \rightarrow \mathrm{AE}(10 \% \\
\mathrm{NaOH}) \rightarrow \text { Dialysis } \rightarrow \text { Freeze-thawing }\end{array}$} & Main chain of $(1 \rightarrow 3)-\beta$-Galp, substituted at O- 6 by $(1 \rightarrow 6)$-linked $\beta$-Galp with side chains of $\alpha$-Araf and & \multirow{4}{*}{ [54] } \\
\hline Black tea & BTPS & & terminal units of $\alpha$-Rhap, $\alpha$-Fucp and $\alpha$-Araf & \\
\hline Green tea & GTPI & & \multirow{2}{*}{ Main chain of $(1 \rightarrow 4)-\beta$-Xylp, substituted in O-3 by $\alpha$-Araf, $\beta$-Galp and $\alpha$-Glcp units } & \\
\hline Black tea & BTPI & & & \\
\hline
\end{tabular}


Table 2. Cont.

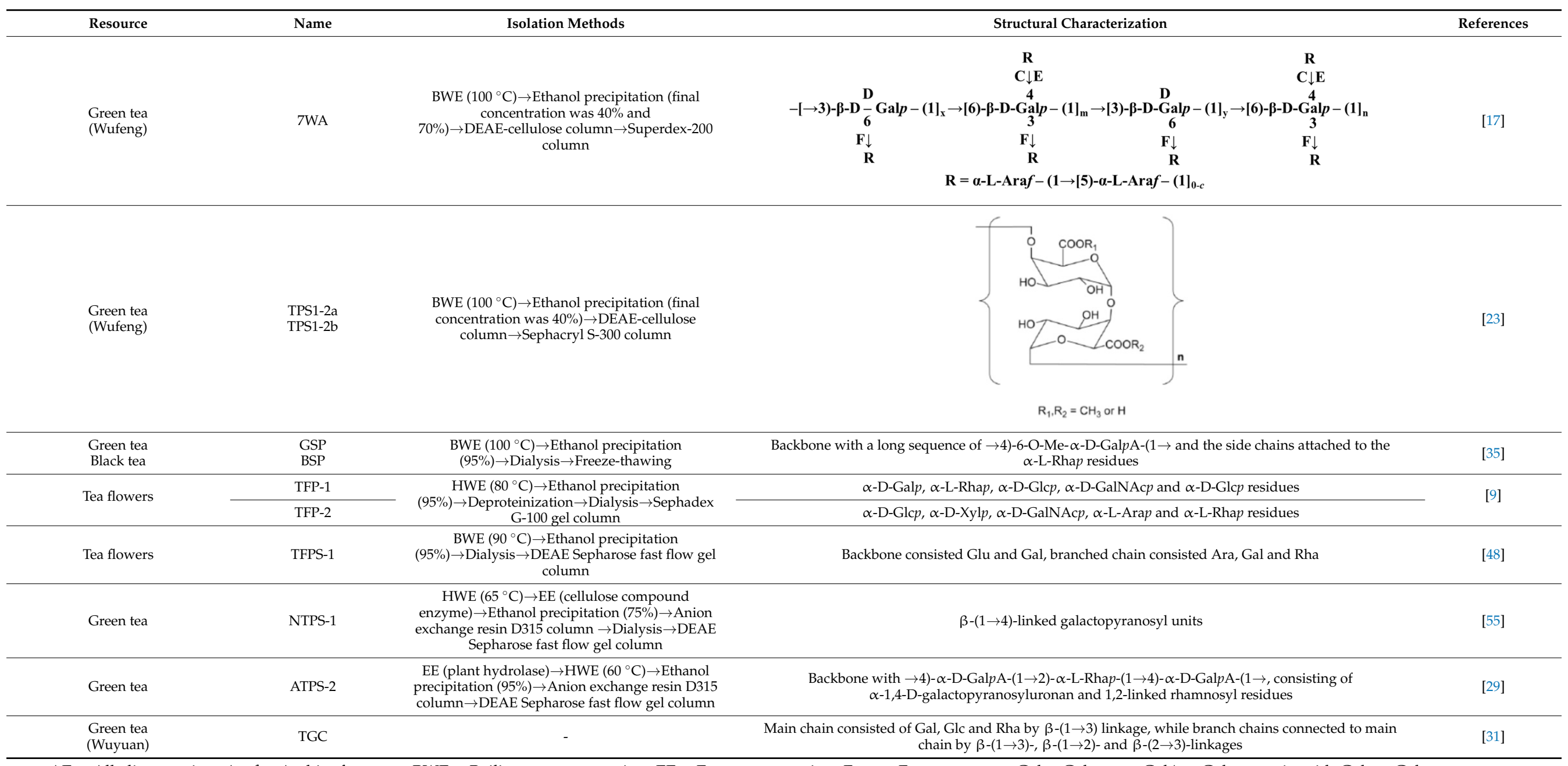

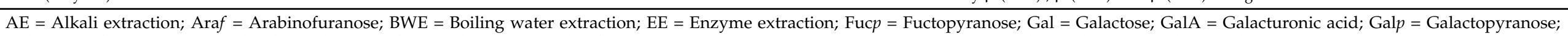

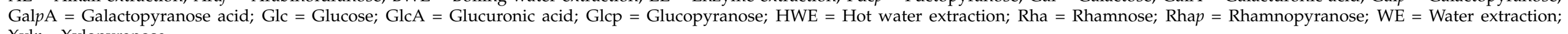
Xyl $p=$ Xylopyranose. 
The structures of TPSs vary due to different tea materials, harvest years, processing methods as well as extraction and purification methods among others. Tables 1 and 2 summarized the factors including tea raw materials, processing technologies and isolation methods that affect the main chemical characteristics of TPSs, such as monosaccharide composition, $\mathrm{M}_{\mathrm{w}}$, and chemical structure.

\subsection{Tea Material}

The monosaccharide composition and $\mathrm{M}_{\mathrm{w}}$ of TPSs differ from different parts of tea (i.e., leaves, flowers, seeds) and different species even in the same category of tea $[10,11,40]$. For instance, the $\mathrm{M}_{\mathrm{w}}$ and monosaccharides of green tea TPSs were found different among species of Xihu Longjing, Huizhoulvcha, Chawentianxia, and others [11].

Tissues of tea-The leaves, flowers and seeds of tea had different profiles of monosaccharide composition and molar ratio of TPSs. Wang et al. analyzed the monosaccharide compositions of TPSs from tea leaves (TLPS), flowers (TFPS) and seeds (TSPS), and found that TLPS was composed of Gal, Fuc, Rha, Ara, Xyl, Man, Rib, GalA, and GlcA with a molar ratio of 1.00:0.29:0.87:1.27:1.77:0.07:0.11:0.3:2.54:0.24; TFPS was composed of Gal, Rha, Ara, Glc, Xyl, Man, GalA, and GlcA with a molar ratio of 1.00:0.42:0.97:0.36:0.11:0.17:0.71:0.08; and TSPS was consisted of Gal, Glc, Rha, Xyl, Ara, GalA, and GlcA with a molar ratio of 1.00:1.95:0.35:0.15:0.95:0.23:0.07 [10]. It was found that the in TPS from leaves had the most types of monosaccharides (nine) than that of TFPS (eight) and TSPS (seven). The molecular weight distribution (MWD) of TLPS, TFPS, and TSPS were ranged from 3.67 to $758 \mathrm{kDa}$, 2.56 to $1460 \mathrm{kDa}$, and 3.66 to $961 \mathrm{kDa}$, respectively, indicating that the $\mathrm{M}_{\mathrm{w}}$ of polysaccharide from tea flowers was the highest [10]. In the same study, they also found that TFPS had higher $\mathrm{M}_{\mathrm{w}}$ than TLPS [45].

Species of tea-TPSs extracted from different species of the same category of tea also had different monosaccharide composition and $\mathrm{M}_{\mathrm{w}}$. For example, the monosaccharide composition of three species of green tea polysaccharides extracted from Xihu Longjing (XTPS), Chawentianxia (CTPS), and Huizhoulvcha (HTPS) was different. XTPS and CTPS were mainly consisted of Rha, Ara, Gal, Glc, Xyl, Man, and GalA with mole ratios of 9.50:8.79:13.17:5.52:1.24:3.52:11.60 and 8.73:11.95:16.53:11.06:1.17:3.81:15.06, respectively, whereas HTPS was consisted of Rha, Ara, Gal, Glc, Xyl, Man, Rib, and GalA with a mole ratio of 9.48:23.06:30.68:7.28:0.96:3.75:4.37:18.36 [11]. Compared to XTPS and CTPS, HTPS contained a new monosaccharide Rib, and the content of Ara, Gal, and GalA was the highest. The green tea polysaccharides from Shufeng, Longjin D, and Jialaoshan were composed of Rha, Ara, Xyl, Man, Gal, and Glu with different mole percentages of 3.15:33.90:3.36:2.45:38.44:18.70, 3.38:32.42:2.80:2.83:41.41:17.17, and 3.53:31.32:2.67:3.14:42.97:16.36, respectively [40]. TPSs from two types of Oolong tea, Fenhuangdanzong and Tieguanyin were composed of Rha, Ara, Xyl, Man, Gal, and Glu in the mole percentages of 3.65:31.70:2.79:2.60:44.87:14.38 and 5.77:32.56:3.81:1.22:46.47:10.18, respectively [40]. There was only difference in the mole percentages for three TPSs from green tea and two TPSs from Oolong tea.

The $M_{w}$ of TPSs is also different among tea species. It was found that the $M_{w}$ of TPSs from three green tea (Shufeng, Longjin, and Jialaoshan) and two oolong tea species (Fenghuangdanzong and Tieguanyin) were 127, 106, 121, 107, and 95, respectively. The $\mathrm{M}_{\mathrm{W}}$ of polysaccharides from Tieguanyin oolong tea was the lowest [40]. Asides from the composition, the $\mathrm{M}_{\mathrm{W}}$ of three green tea polysaccharides extracted from above mentioned XTPS, CTPS, and HTPS was also different as described in the following. XTPS was mainly consisted of three kinds of polysaccharides with the $\mathrm{M}_{\mathrm{w}}$ of $810,54.5$, and $1.26 \mathrm{kDa}$, respectively; CTPS was mainly consisted of four kinds of polysaccharides with the $\mathrm{M}_{\mathrm{w}}$ of 805,138 , 19 , and $12 \mathrm{kDa}$, respectively; and HTPS was composed of four kinds of polysaccharides with the $M_{w}$ of $771,137,11$, and $1.2 \mathrm{kDa}$, respectively [11]. It was observed that the $\mathrm{M}_{\mathrm{w}}$ of CTPS was generally higher than that of XTPS and HTPS in corresponding TPS range.

There is very limited research on the chemical structures of TPSs related to tea materials. In Scoparo's study, the chemical structures of two kinds of polysaccharides from 
green (GSP) and black (BSP) teas were characterized and found that they both consisted of rhamnogalacturonan as the backbone containing a long sequence of $\rightarrow 4$ )-6-O-Me- $\alpha$ GalpA- $(1 \rightarrow$ and interrupted by $\alpha$-L-Rhap residues. The difference was that GSP contained $65 \%$ GalA residues in comparison to only one third of GalA from BSP [35]. It is likely resulted from the oxidation during the processing of black tea, leading to the degradation of uronic acid.

\subsection{Processing Technologies}

Technology of tea process is another influencing factor on physicochemical characterization of TPSs. The monosaccharide composition and $\mathrm{M}_{\mathrm{w}}$ can vary among TPSs extracting from teas with different processing procedures such as fermentation, aging, extrusion processing and selenium-rich technologies [8,12,28,43,50].

Fermentation-The composition and content of monosaccharides are different in the TPSs of unfermented green tea (GTPS), semifermented oolong tea (OTPS), and fermented black tea (BTPS). For example, the composition and molecular ratio of the main monosaccharides were found (i) GTPS: D-Rha, L-Ara, D-Xyl, D-Man, D-Gal, and D-Glc, with a ratio of 7.8:41.8:7.1:7.3:18.7:17.0; (ii) OTPS: D-Rha, L-Ara, D-Gal, and D-Glc, with a ratio of 16.2:43.7:18.0:21.9; and (iii) BTPS: D-Rha, L-Ara, D-Gal, and D-Glc, with a ratio of 14.4:36.4:19.7:29.4 [8]. It was found that OTPS and BTPS contained no D-Xyl and D-Man, suggesting fermentation had a significant impact on these two monosaccharides. The MWD of GTPS, OTPS, and BTPS was ranged from 9.2 to $251.5 \mathrm{kDa}$, from 5.3 to $100.9 \mathrm{kDa}$ and from 3.8 to $32.7 \mathrm{kDa}$, respectively [8]. MWD was decreased with the increase of the fermentation degree, indicating that the glycosidic bonds in the backbone were cleaved during the fermentation process, and the larger degree of fermentation, the more cleavage. Moreover, the different degree of fermentation in the same category of oolong tea also resulted in discrepancies among corresponding TPSs. For instance, the polysaccharides from three oolong teas, namely, Tieguanyin (TTPS), Fenghuangdancong (FTPS), and Dahongpao (DTPS) with light, intermediate, and high degree of fermentation, respectively, were composed of mainly L-Rha, D-Fuc, L-Ara, D-Xyl, D-Man, D-Glc, and D-Gal with different molar ratios of 5.75:1.96:26.84:0.81:2.91:26.39:35.34, 10.83:3.83:25.69:2.39:6.97:14.44:35.85, and 10.31:5.09:22.93:0.28:5.21:22.59:33.59, respectively [50]. Therefore, the fermentation degree of tea effectively affected the molar ratio of monosaccharides of TPS, and the content of D-Xyl and D-Man decreased with the increasing of fermentation degree. Aside from that, the $\mathrm{M}_{\mathrm{w}}$ of TTPS, FTPS, and DTPS was different: TTPS contained one major peak of $92.9 \%$ with $\mathrm{M}_{\mathrm{w}}$ of $8.17 \times 10^{5} \mathrm{Da}$ and two minor peaks with $\mathrm{M}_{\mathrm{w}}$ of $0.25 \times 10^{5}$ $(4.5 \%)$ and $0.07 \times 10^{5} \mathrm{Da}(2.7 \%)$; FTPS had two peaks with $\mathrm{M}_{\mathrm{w}}$ of $9.30 \times 10^{5}(34.2 \%)$ and $0.14 \times 10^{5}(65.8 \%) \mathrm{Da}$; and DTPS consisted of one major peak $94.4 \%$ with $\mathrm{M}_{\mathrm{w}}$ of $26.4 \times 10^{5} \mathrm{Da}$ and two minor peaks with $\mathrm{M}_{\mathrm{w}}$ of $1.10 \times 10^{5}(4.3 \%)$ and $0.42 \times 10^{5} \mathrm{Da}$ $(1.4 \%)$, respectively. The largest $\mathrm{M}_{\mathrm{W}}$ of oolong tea polysaccharides came from Dahongpao with the highest degree of fermentation [50]. The increased degree of fermentation decreased the $\mathrm{M}_{\mathrm{w}}$ (or MWD), an opposite pattern from above mentioned TPSs from green, oolong, and black tea. Within the category of oolong tea, the reported data from the measurement of three oolong tea TPSs revealed that the increased $M_{w}$ with the increased degree of fermentation, may result from three different species of tea prior to fermentation process, because the three brands of oolong tea in this example came from different regions of China. Species of tea plays more important roles in the composition and molecular weight than process in general.

Aging time-One of the characteristics of pu-erh tea is aging. Xu et al. (2014) studied the monosaccharide composition of polysaccharide isolated from pu-erh tea (PTPSs) with aging of mild fermentation for one year (PTPS-1), three years (PTPS-3), and five years (PTPS-5). The monosaccharide composition analysis showed that PTPS-1, PTPS-3, and PTPS-5 consisted of L-Rha, L-Ara, D-Xyl, D-Man, D-Gal, D-Glc, and D-Fuc with different molar ratios of 5.34:21.86:4.04:21.59:26.93:16.52:3.64, 6.82:26.22:0.35:13.83:39.34:10.23:3.21, and 15.98:20.84:0.15:15.29:40.33:6.08:1.68, respectively [12]. The monosaccharide composi- 
tion of PTPS-1, PTPS-3, and PTPS-5 was the same, while the content of each monosaccharide was different. PTPS-1, PTPS-3, and PTPS-5 had different Mw. PTPS-1 had one major fraction of $92 \%$ with the $\mathrm{M}_{\mathrm{w}}$ of $2.7 \times 10^{6} \mathrm{Da}$; PTPS-3 had two major fractions with $\mathrm{M}_{\mathrm{w}}$ of $6.31 \times 10^{5} \mathrm{Da}(52 \%)$ and $1.93 \times 10^{6} \mathrm{Da}(47 \%)$, respectively; PTPS-5 also had two major fractions with $\mathrm{M}_{\mathrm{w}}$ of $1.16 \times 10^{6}(60 \%)$ and $3.9 \times 10^{6} \mathrm{Da}(33 \%) \mathrm{Da}$, respectively [12]. Time of aging changed TPSs in different directions in terms of molecular weight, but more study was required to measure the molecular weight and amount of TPSs in the same time and then to correlate the MWD and the aging time, which could yield a conclusive pattern and reveal the relationship between aging or degree of fermentation with $\mathrm{M}_{\mathrm{w}}$ in the comparison of same species.

Extrusion-The extrusion processing also influences the monosaccharide composition of polysaccharide from coarse tea [43]. Three kinds of TPS were extracted from untreated tea (TPSU), tea extruded at the conditions of $4 \%$ moisture content and $160{ }^{\circ} \mathrm{C}$ (TPSE4) and tea extruded at the conditions of $12 \%$ moisture content and $100{ }^{\circ} \mathrm{C}$ (TPSE12), respectively. The three kinds of polysaccharide samples were all composed of Rha, Ara, Man, Glc, Gal, and uronic acid. Extrusion treatment of the coarse tea resulted in the change of molar ratios on monosaccharide composition, which was 0.12:0.93:0.13:1.00:0.62:1.46, 0.20:1.11:0.18:1.00:0.63:1.23 and 0.88:1.19:0.34:1.00:1.00:1.93 for TPSE4, TPSE12, and TPSU, respectively. The MWD of TPSU, TPSE4, and TPSE12 was $0.1 \times 10^{4}$ to $33.0 \times 10^{4} \mathrm{Da}$, $1.5 \times 10^{4}$ to $33.0 \times 10^{4} \mathrm{Da}$ and $0.4 \times 10^{4}$ to $40.5 \times 10^{4} \mathrm{Da}$, respectively, suggesting that extrusion treatment might destroy the cell structure and the high molecular weight polysaccharides were easily extracted [43].

Selenium enrichment-Selenium also has impact on the composition and structure of TPS. The monosaccharide composition of two Se-enriched tea polysaccharides (Se-TPS) extracted from artificial (ASe-TPS2) and natural Se-enriched teas (NSe-TPS2) were analyzed and found that ASe-TPS2 was composed of Rha, Ara, Glc, Xyl, and GalA in the molar ratio of 1.93:7.05:1.00:1.05:26.12, whereas NSe-TPS2 was consisted of Fuc, Rha, Ara, Gal, Glc, GlcA, and GalA in the molar ratio of 0.07:0.28:0.59:1.00:0.10:0.49:1.24 [28]. The main monosaccharide compositions of ASe-TPS2 were Ara and GalA, and the galacturonic acid was the highest among all five groups of monosacchrides. The main monosaccharides of NSe-TPS2 were Ara, Gal, GlcA, and GalA. The $\mathrm{M}_{\mathrm{w}}$ of ASe-TPS2 and NSe-TPS2 was $6.73 \times 10^{3} \mathrm{Da}$ and $2.44 \times 10^{5} \mathrm{Da}$, respectively, indicating that the $\mathrm{M}_{\mathrm{w}}$ of Se-TPS from artificially Se-enriched green tea was smaller than that of Se-TPS from naturally Se-enriched green tea [28].

There are a few reports on the influence of processing technology on the chemical structure of TPSs. The selenylation method was found to affect the chain structures of TPSs [28]. The ASe-TPS2 extracted from artificially Se-enriched green tea was composed of $\beta$-D-(1 $\rightarrow 3)$-Glcp, $\alpha$-D-( $1 \rightarrow 4)$-GalpA, $(1 \rightarrow 4)$-Glcp, $\alpha$-L-(1 $\rightarrow 2,3)$-Araf, $\alpha$-L-( $1 \rightarrow 2)$-Rhap, and $\alpha$-D- $(1 \rightarrow 4)-$ GalpA, and non-reducing ends were consisted of Araf and Xylp, whereas the NSe-TPS2 extracted from naturally Se-enriched green tea was composed of $\beta$-D- $(1 \rightarrow 4)-$ Glcp and $\alpha$-D- $(1 \rightarrow 4)$-GalpA, and the branches were mainly composed of $\beta$-L-( $1 \rightarrow 2)$-Araf, $\alpha$-D-( $1 \rightarrow 3)-G a l p$, and $\beta$-L-( $1 \rightarrow 2)$-Rhap, and the non-reducing ends were mainly composed of Glcp and Galp residues. The difference between ASe-TPS2 and NSe-TPS2 may be influenced by the Se element.

\subsection{Isolation Methods}

The monosaccharide composition, molar contents, $\mathrm{M}_{\mathrm{W}}$ and chemical structures of TPSs are different under different isolation methods, which are listed in Tables 1 and 2.

Extraction methods-Tea polysaccharide conjugates can be extracted with water or alkali solution, containing neutral sugars, uronic acid, and protein. Water-soluble TPS conjugates (TPC-W) and alkali-soluble TPS conjugates (TPC-A) were extracted from green tea by hot water and alkali solution respectively [39]. The TPC-W and TPC-A were both composed of seven monosaccharides, namely Rha, Fuc, Ara, Xyl, Man, Glc, and Gal with different molar ratios of 8.74:4.69:29.04:0.42:7.11:14.10:35.89 and 13.81:1.43:36.07:5.24:4.89:6.28:32.27, re- 
spectively [39]. The difference in monosaccharide composition between them was not much, but there was a significant difference in molecular weight. TPC-W had three homogeneous components with the $\mathrm{M}_{\mathrm{w}}$ of $6.62 \times 10^{3}(56.07 \%), 4.85 \times 10^{4}(6.54 \%)$, and $4.55 \times 10^{6}(37.38 \%)$ $\mathrm{Da}$, respectively; TPC-A was consisted of four homogeneous components with the $\mathrm{M}_{\mathrm{W}}$ of $4.13 \times 10^{3}(17.14 \%), 1.12 \times 10^{4}(11.43 \%), 6.77 \times 10^{4}(2.86 \%)$, and $4.94 \times 10^{6}(68.57 \%) \mathrm{Da}$, respectively. Hence, the higher $\mathrm{M}_{\mathrm{W}}$ of TPC was more efficiently extracted by alkali solution than water [39]. Wang, Yang, and Wei studied the monosaccharide composition of polysaccharides from leaves and flowers of green tea obtained by different extraction methods [45]. The polysaccharides from leaves with hot water (HWE-TLPS) and boiled water extraction (BWE-TLPS) were composed of Rha, Ara, Gal, Glu, Xyl, Man, GalA, and GluA with molar ratios of 4.82:0.22:2.93:1.00:0.21:0.48:2.06:0.22 and 0.50:1.04:1.38:1.00:0.06:0.22:1.48:0.09, respectively. The polysaccharide extracted from tea leaves with enzyme extraction method (EE-TLPS) was composed of Rha:Ara:Gal:Glu:GalA:GluA and the corresponding molar ratio was 1.09:1.80:2.27:1.00:2.36:0.12. Xyl and Man were not found in EE-TLPS, indicating that $\mathrm{Xyl}$ and Man were easily destroyed under the enzymatic extraction conditions. The polysaccharides extracted from tea flowers with hot water (HWE-TFPS), boiling water (BWETFPS), and enzyme extraction (EE-TFPS) were all composed of Rha, Ara, Gal, Glu, Xyl, Man, GalA, and GluA with different molar ratios of 0.36:1.19:2.09:1.00:0.16:0.23:0.25:0.12, 0.80:2.06:2.47:1.00:0.20:0.25:2.20:0.13, and 1.33:2.90:3.20:1.00:0.24:0.21:2.10:0.12, respectively [45]. The content of Rha, Ara, and Gal in EE-TFPS increased due to the effect of enzyme. HWE-TLPS and BWE-TLPS were mainly consisted of three kinds of monosaccharide components with the $\mathrm{M}_{\mathrm{W}}$ of 1.165, 104, and $413 \mathrm{kDa}$ (HWE-TLPS) and 1.04, 138, and $458 \mathrm{kDa}$ (BWE-TLPS), respectively. EE-TLPS was mainly made up of five components with the molecular weight of 1.023, 49.3, 75.9, 151, and $487 \mathrm{kDa}$. HWE-TFPS, BWE-TFPS, and EE-TFPS were mainly consisted of four monosaccharides with the molecular weight of 483, 168, 120, and $1.059 \mathrm{kDa}$ (HWE-TFPS); 508, 168, 120, and $1.059 \mathrm{kDa}$ (BWE-TFPS); and $465,157,129$, and $1.176 \mathrm{kDa}$ (EE-TFPS), respectively [45]. It can be seen that the $\mathrm{M}_{\mathrm{w}}$ of polysaccharides using enzyme extraction were decreased, indicating that enzyme catalyzed cleavage of TPS bonds occurred in the extraction process. Three tea flower polysaccharides (TFPS) were prepared by traditional water extraction (TWE-TFPS), microwave assisted extraction (MAE-TFPS), and ultrasound assisted extraction (UAE-TFPS), respectively. The peak $\mathrm{M}_{\mathrm{W}}$ from TWE-TFPS was 4.4 and $31 \mathrm{kDa}$. Comparing with TWE-TFPS, the peak $\mathrm{M}_{\mathrm{W}}$ from UAE-TFPS decreased with the increasing ultrasonic power, whereas the peak $M_{W}$ from MAE-TFPS increased with the augment of microwave power, demonstrating that radio waves have significant effects on the $\mathrm{M}_{\mathrm{W}}$ of TPS [56].

Purification methods-Isolation methods will also have dramatic influence on the $\mathrm{M}_{\mathrm{w}}$ and chemical structures of TPSs (Table 2). In Gao's study, the $\mathrm{M}_{\mathrm{w}}$ of the TPS from five subfractions isolated and purified with different concentrations of $\mathrm{NaCl}$ aqueous solution $(0,0.1,0.2,0.3$, and $0.4 \mathrm{M})$ from a local Chinese tea (Zhongcha \#108) was 51.85, $40.0,32.72,25.27$, and $18.38 \mathrm{kDa}$, respectively, and the $\mathrm{M}_{\mathrm{w}}$ was decreased with the increase of the concentration of $\mathrm{NaCl}$ solution [5]. The stronger ionic strength of the solution yielded the lower Mw of TPS, indicating that the solubility of large TPS is lower than that of small TPS in strong ionic solution. From the crude tea polysaccharide (NTPS) of green tea, a neutral polysaccharide (NTPS-1) was extracted with plant hydrolase and precipitated by $95 \%$ aqueous ethanol, and NTPS- 1 was a galactan consisting of $\beta-(1 \rightarrow 4)$ linked galactopyranosyl units [55]. An acidic polysaccharide (ATPS-2) was extracted with cellulose compound enzyme and precipitated with $75 \%$ aqueous ethanol from green tea. The backbone of ATPS-2 was $\rightarrow 4)$ - $\alpha$-D-GalpA-( $1 \rightarrow 2)$ - $\alpha$-L-Rhap-( $1 \rightarrow 4)$ - $\alpha$-D-GalpA-( $1 \rightarrow$ and the side chains attached to the $\alpha$-L-Rhap residues, which was quite different compared with NTPS-1 [29]. Two homogenous water-soluble polysaccharides (TPS1-2a and TPS1-2b) from green tea leaves were isolated from crude tea polysaccharides (TPS1) extracted with hot water and followed by $40 \%$ of aqueous ethanol precipitation after purification with gel permeation. TPS1-2a and TPS1-2b were homogalacturonan (HG) pectins consisting of $(1 \rightarrow 4)-\alpha$-D-GalA residues as backbone with $28.4 \%$ and $26.1 \%$ of carboxyl groups as 
methyl ester, respectively [23]. The investigation of the chemical structures of water soluble fractions (GTPS and BTPS) and insoluble fractions (GTPI and BTPI) from green and black teas found that soluble fractions GTPS and BTPS were consisted of a main chain of $(1 \rightarrow 3)-\beta$-Galp with side chains of $\alpha$-Araf and terminal units of $\alpha$-Araf, $\alpha$-Fucp and $\alpha$-Rhap substituted at O-6 by $(1 \rightarrow 6)$-linked- $\beta$-Galp, whereas water insoluble fractions, GTPI and BTPI were composed of a main chain of $(1 \rightarrow 4)-\beta-X y l p$, substituted at O-3 by $\alpha$-Araf, $\beta$-Galp, and $\alpha$-Glcp units [54]. In another study, two polysaccharide fractions termed TFP-1 and TFP-2, were separated from Sephadex G-100 column chromatography from the crude polysaccharide (TFP), which was extracted from tea flower by boilingwater extraction and ethanol precipitation. It was found that TFP- 1 contained $\alpha$-L-Rhap, $\alpha$-D-Galp, $\alpha$-D-GalpNAc, $\alpha$-D-Xylp, $\alpha$-D-Glcp, and $\beta$-D-Glcp residues, whereas TFP- 2 is composed of $\alpha$-L-Rhap, $\alpha$-L-Arap, $\alpha$-D-Xylp, $\alpha$-D-Glcp, and $\alpha$-D-GlcpNAc residues [9], illustrating that the separation methods play an important role in the composition and structures of TPSs, reminiscent of small molecular separation.

Drying methods-Four polysaccharides were isolated from tea leaves using freezedrying (TPS-F), vacuum-drying (TPS-V), spray-drying (TPS-S), and microwave-vacuum drying (TPS-M), respectively. These four crude tea polysaccharides were all composed of Rha, Rib, Ara, Glc, Xyl, Gal, Man, GalA, and GluA with different molecular ratios of 1.0:0.58:2.77:2.82:0.14:2.44:0.45:3.88:0.26, 1.0:0.47:2.62:5.96:0.16:3.43:0.51:3.0:0.20, 1.0:0.46:2.43: 0.77:0.10:3.24:0.40:1.94:0.18, and 1.0:0.29:1.90:1.30:0.15:2.97:0.40:1.66:0.16, respectively [44]. The content of GalA and GluA in TPS-S and TPS-M were lower than TPS-F and TPSV. TPS-F, TPS-V, TPS-S, and TPS-M showed similar molecular weight distribution and mainly contained four distinct peaks with groups of molecular weights around $9.2 \times 10^{5}$, $2.2 \times 10^{5}, 3.0 \times 10^{4}$, and $0.34 \times 10^{4} \mathrm{Da}$, respectively [44]. The difference of monosaccharide ratio and MWD can be resulted from the different drying methods of TPSs.

\section{Applications of TPSs}

TPSs have a variety of biological activities, such as antioxidant [3], hypoglycemia [15], anti-fatigue [18], anti-obesity [20], prebiotics [57], and immunomodulatory effect [24], it can be added to food as a functional ingredient to prepare health products. At the same time, TPS is a good emulsifier, which can be used in food, cosmetic and pharmaceutical industry. In Chen's study, an alkali-extracted tea polysaccharide conjugates (TPC-A) was used to stabilize oil-in-water emulsions, and found TPC-A had a favorable protective effect on catechins and can be used as a natural emulsifier [58]. Li et al. (2021) also obtained a natural antioxidant emulsifier from Chin brick tea, tea polysaccharide conjugate (TPC) possessed a good emulsifying properties with excellent antioxidant activity, which can be used as dual-purpose antioxidant emulsifiers [59]. In addition, TPSs can be used as feed additives in the poultry and feed industry to enhance animal immunity and improve meat quality. For example, a green tea polysaccharide conjugates (GTPC) was extracted from Yingshan Yunwu tea could improve immune status, intestinal microflora and meat quality in chickens [60]. Moreover, in the biomedical industry, TPSs can be used as a drug delivery agent. In Li's work, a biodegradable, non-toxic and environmental-friendly PTX loaded nanoparticle was prepared using TPS as the shell and zein as the core, it was found that TPS would be a promising agent in the drug delivery system [61]. Wu et al. (2018) also synthesized a cationic branched tea polysaccharide derivative (CTPSA), which exhibited lower cytotoxicity and can be used as a nonviral vector for the delivery of siRNA to the liver [62]. However, the application of TPSs are few or even a blank in other fields such as wound treatment, antiviral preparations, fertilizers, etc. which may be related with the complexity of TPSs structure and unclear structure-activity relationship of TPSs. Therefore, a lot of work needs to be done to develop the potential application of TPSs in the future.

\section{Conclusions}

The different structures of TPSs obtained in various reports are due to different tea raw materials, processing technologies, and isolation methods. The structural features of 
TPSs differ from different teas, even different parts and categories of the same tea. The structures of TPSs obtained with different degree of fermentation and extraction methods could have vast differences. Therefore, it is critical to clarify how the fermentation process affects the structure of TPSs and find an optimal method to obtain targeted TPSs with higher bioactivities. Due to the multiple influencing factors discussed in this review and the complex structures of TPSs, it is currently impossible to predict and also quite difficult to determine the structures of TPSs, especially high-level structures. Moreover, it is unrealistic to speculate the efficacy of TPSs without the characterization and actual biological testing of isolated TPSs. Thus, a large number of experiments are required to identify the complete structures of TPSs and to further evaluate the bioactivity of characterized TPSs. Furthermore, most of the researches focused on the polysaccharides from green tea, whereas the studies about polysaccharides from other teas are scarce. Therefore, more studies should be also focused on the characterization, identification, and comparison of the structures of TPSs from different teas with different processing technologies and isolation methods to have a comprehensive evaluation and understanding of the factors influencing the structures and biological properties of TPSs and broaden their applications in various fields.

Funding: This work was supported by the Grant from Hubei Province, China (grant no. 2019ABA100), Assessment and Comprehensive Utilization of Characteristic Biological Resources in Dabie Mountains (4022019006), Natural Science Fund of Hubei Province (2019CFB395), Open Program of Key Laboratory of Cultivation and High-value Utilization of Marine Organisms in Fujian Province (2019fjscq07).

Conflicts of Interest: The authors declare no conflict of interest.

$\begin{array}{ll}\text { Abbreviations } \\ \text { AFM } & \text { Atomic force microscopy } \\ \text { Ara } & \text { Arabinose } \\ \text { BWE } & \text { Boiling water extraction } \\ \text { EE } & \text { Enzyme extraction } \\ \text { FT-IR } & \text { Fourier transform infrared spectroscopy } \\ \text { Fuc } & \text { Fucose } \\ \text { Glc } & \text { Glucose } \\ \text { Gal } & \text { Galactose } \\ \text { GalA } & \text { Galacturonic acid } \\ \text { GluA } & \text { Glucuronic acid } \\ \text { GC } & \text { Gas chromatography } \\ \text { GC-MS } & \text { GC-mass spectroscopy } \\ \text { GFC } & \text { Gel-filtration chromatography } \\ \text { GPC } & \text { Gel permeation chromatography } \\ \text { HG } & \text { Homogalacturonan } \\ \text { HWE } & \text { Hot water extraction } \\ \text { Man } & \text { Mannose } \\ \text { MAE } & \text { Microwave-assisted extraction } \\ \text { MLLS } & \text { Multiangle laser light-scattering instrument } \\ \text { M } & \text { Molecular weight } \\ \text { MWD } & \text { Molecular weight distribution } \\ \text { NMR } & \text { Nuclear magnetic resonance spectroscopy } \\ \text { Rha } & \text { Rhamnose } \\ \text { Rib } & \text { Ribose } \\ \text { TFA } & \text { Trifluoroacetic acid } \\ \text { TPC } & \text { Tea polysaccharide conjugates } \\ \text { TPS } & \text { Tea polysaccharides } \\ \text { TWE } & \text { Traditional water extraction } \\ \text { TEM } & \text { Transmission electron microscopy } \\ \text { UAE } & \text { Ultrasound-assisted extraction } \\ \text { Xyl } & \text { Xylose } \\ & \end{array}$




\section{References}

1. Zhang, L.; Ho, C.-T.; Zhou, J.; Santos, J.S.; Armstrong, L.; Granato, D. Chemistry and biological activities of processed Camellia sinensis teas: A comprehensive review. Compr. Rev. Food Sci. Food Saf. 2019, 18, 1474-1495. [CrossRef]

2. Xiao, J.B.; Jiang, H. A review on the structure-function relationship aspect of polysaccharides from tea materials. Crit. Rev. Food Sci. Nutr. 2015, 55, 930-938. [CrossRef]

3. Yang, X.; Huang, M.; Qin, C.; Lv, B.; Mao, Q.; Liu, Z. Structural characterization and evaluation of the antioxidant activities of polysaccharides extracted from Qingzhuan brick tea. Int. J. Biol. Macromol. 2017, 101, 768-775. [CrossRef]

4. Chen, G.; Yuan, Q.; Saeeduddin, M.; Ou, S.; Zeng, X.; Ye, H. Recent advances in tea polysaccharides: Extraction, purification, physicochemical characterization and bioactivities. Carbohydr. Polym. 2016, 153, 663-678. [CrossRef] [PubMed]

5. Gao, Y.; Zhou, Y.; Zhang, Q.; Zhang, K.; Peng, P.; Chen, L.; Xiao, B. Hydrothermal extraction, structural characterization, and inhibition HeLa cells proliferation of functional polysaccharides from Chinese tea Zhongcha 108. J. Funct. Foods 2017, 39, 1-8. [CrossRef]

6. Nie, S.-P.; Xie, M.-Y. A review on the isolation and structure of tea polysaccharides and their bioactivities. Food Hydrocoll. 2011, 25, 144-149. [CrossRef]

7. Nie, S.; Cui, S.W.; Xie, M. Chapter 7-Tea polysaccharide. In Bioactive Polysaccharides; Nie, S., Cui, S.W., Xie, M., Eds.; Academic Press: London, UK, 2018; pp. 349-394.

8. Chen, H.; Qu, Z.; Fu, L.; Dong, P.; Zhang, X. Physicochemical properties and antioxidant capacity of 3 polysaccharides from green tea, oolong tea, and black tea. J. Food Sci. 2009, 74, C469-C474. [CrossRef] [PubMed]

9. Quan, H.; Yu, Q.Y.; Jiang, S.; Xiong, C.Y.; Ling, Z.J.; He, P.M. Structural characterization and antioxidant activities of 2 watersoluble polysaccharide fractions purified from tea (Camellia sinensis) flower. J. Food Sci. 2011, 76, C462-C471. [CrossRef] [PubMed]

10. Wang, Y.; Mao, F; Wei, X. Characterization and antioxidant activities of polysaccharides from leaves, flowers and seeds of green tea. Carbohydr. Polym. 2012, 88, 146-153. [CrossRef]

11. Xiao, J.; Huo, J.; Jiang, H.; Yang, F. Chemical compositions and bioactivities of crude polysaccharides from tea leaves beyond their useful date. Int. J. Biol. Macromol. 2011, 49, 1143-1151. [CrossRef]

12. Xu, P.; Wu, J.; Zhang, Y.; Chen, H.; Wang, Y. Physicochemical characterization of puerh tea polysaccharides and their antioxidant and $\alpha$-glycosidase inhibition. J. Funct. Foods 2014, 6, 545-554. [CrossRef]

13. Yang, K.; Li, Y.-W.; Gao, Z.-Y.; Xiao, W.; Li, T.-Q.; Song, W.; Zheng, J.; Chen, H.; Chen, G.-H.; Zou, H.-Y. MiR-93 functions as a tumor promoter in prostate cancer by targeting disabled homolog 2 (DAB2) and an antitumor polysaccharide from green tea (Camellia sinensis) on their expression. Int. J. Biol. Macromol. 2019, 125, 557-565. [CrossRef] [PubMed]

14. Yang, K.; Gao, Z.-Y.; Li, T.-Q.; Song, W.; Xiao, W.; Zheng, J.; Chen, H.; Chen, G.-H.; Zou, H.-Y. Anti-tumor activity and the mechanism of a green tea (Camellia sinensis) polysaccharide on prostate cancer. Int. J. Biol. Macromol. 2019, 122, 95-103. [CrossRef] [PubMed]

15. Li, S.; Chen, H.; Wang, J.; Wang, X.; Hu, B.; Lv, F. Involvement of the PI3K/Akt signal pathway in the hypoglycemic effects of tea polysaccharides on diabetic mice. Int. J. Biol. Macromol. 2015, 81, 967-974. [CrossRef] [PubMed]

16. Zhu, J.; Chen, Z.; Zhou, H.; Yu, C.; Han, Z.; Shao, S.; Hu, X.; Wei, X.; Wang, Y. Effects of extraction methods on physicochemical properties and hypoglycemic activities of polysaccharides from coarse green tea. Glycoconj. J. 2020, 37, 241-250. [CrossRef]

17. Wang, H.; Shi, S.; Bao, B.; Li, X.; Wang, S. Structure characterization of an arabinogalactan from green tea and its anti-diabetic effect. Carbohydr. Polym. 2015, 124, 98-108. [CrossRef]

18. Chi, A.; Li, H.; Kang, C.; Guo, H.; Wang, Y.; Guo, F.; Tang, L. Anti-fatigue activity of a novel polysaccharide conjugates from Ziyang green tea. Int. J. Biol. Macromol. 2015, 80, 566-572. [CrossRef]

19. Cai, W.; Xie, L.; Chen, Y.; Zhang, H. Purification, characterization and anticoagulant activity of the polysaccharides from green tea. Carbohydr. Polym. 2013, 92, 1086-1090. [CrossRef]

20. Xu, Y.; Zhang, M.; Wu, T.; Dai, S.D.; Xu, J.; Zhou, Z. The anti-obesity effect of green tea polysaccharides, polyphenols and caffeine in rats fed with a high-fat diet. Food Funct. 2015, 6, 297-304. [CrossRef]

21. Yin, L.; Fu, S.; Wu, R.; Wei, S.; Yi, J.; Zhang, L.-M.; Yang, L. A neutral polysaccharide from green tea: Structure, effect on $\alpha$-amylase activity and hydrolysis property. Arch. Biochem. Biophys. 2020,687, 108369. [CrossRef]

22. Yin, L.; Fu, S.; Wu, R.; Wei, S.; Yi, J.; Zhang, L.-M.; Yang, L. Chain conformation of an acidic polysaccharide from green tea and related mechanism of $\alpha$-amylase inhibitory activity. Int. J. Biol. Macromol. 2020, 164, 1124-1132. [CrossRef]

23. Wang, H.; Wei, G.; Liu, F.; Banerjee, G.; Joshi, M.; Bligh, S.W.A.; Shi, S.; Lian, H.; Fan, H.; Gu, X.; et al. Characterization of two homogalacturonan pectins with immunomodulatory activity from green tea. Int. J. Mol. Sci. 2014, 15, 9963-9978. [CrossRef] [PubMed]

24. Chen, G.; Bai, Y.; Zeng, Z.; Peng, Y.; Zhou, W.; Shen, W.; Zeng, X.; Liu, Z. Structural characterization and immunostimulatory activity of heteropolysaccharides from Fuzhuan Brick tea. J. Agric. Food. Chem. 2021, 69, 1368-1378. [CrossRef]

25. Chen, M.; Xiong, L.Y. Supercritical extraction technology in tea polysaccharide extracting application. Adv. Mater. Res. 2012, 347, 1683-1688. [CrossRef]

26. Wei, X.; Yang, Z.; Guo, Y.; Xiao, J.; Wang, Y. Composition and biological activity of tea polysaccharides obtained by water extraction and enzymatic extraction. Lat. Am. J. Pharm. 2010, 29, 117-121. 
27. Wang, J.; Liu, W.; Chen, Z.; Chen, H. Physicochemical characterization of the oolong tea polysaccharides with high molecular weight and their synergistic effects in combination with polyphenols on hepatocellular carcinoma. Biomed. Pharmacother. 2017, 90, 160-170. [CrossRef] [PubMed]

28. Zhu, J.; Chen, Z.; Chen, L.; Yu, C.; Wang, H.; Wei, X.; Wang, Y. Comparison and structural characterization of polysaccharides from natural and artificial Se-enriched green tea. Int. J. Biol. Macromol. 2019, 130, 388-398. [CrossRef]

29. Wang, Y.; Wei, X.; Jin, Z. Structure analysis of an acidic polysaccharide isolated from green tea. Nat. Prod. Res. 2009, 23, 678-687. [CrossRef]

30. Gu, Y.; Qiu, Y.; Wei, X.; Li, Z.; Hu, Z.; Gu, Y.; Zhao, Y.; Wang, Y.; Yue, T.; Yuan, Y. Characterization of selenium-containing polysaccharides isolated from selenium-enriched tea and its bioactivities. Food Chem. 2020, 316, 126371. [CrossRef]

31. Peng, Z.; Xie, M.; Nie, S.; Wang, X. Primary structure and configuration of tea polysaccharide. Sci. China Ser. C Life Sci. 2004, 47, 416-424.

32. Wang, Y.; Li, Y.; Liu, Y.; Chen, X.; Wei, X. Extraction, characterization and antioxidant activities of Se-enriched tea polysaccharides. Int. J. Biol. Macromol. 2015, 77, 76-84. [CrossRef] [PubMed]

33. Chen, X.; Shao, S.; Xie, J.; Yuan, H.; Li, Q.; Wu, L.; Wu, Z.; Yuan, H.; Jiang, Y. Analysis of protein moiety of polysaccharide conjugates water-extracted from low grade green tea. Chem. Res. Chin. Univ. 2018, 34, 691-696. [CrossRef]

34. Wu, S.; Lai, M.; Luo, J.; Pan, J.; Zhang, L.-M.; Yang, L. Interactions between $\alpha$-amylase and an acidic branched polysaccharide from green tea. Int. J. Biol. Macromol. 2017, 94, 669-678. [CrossRef] [PubMed]

35. Scoparo, C.T.; de Souza, L.M.; Rattmann, Y.D.; Dartora, N.; Paiva, S.M.M.; Sassaki, G.L.; Gorin, P.A.J.; Iacomini, M. Polysaccharides from green and black teas and their protective effect against murine sepsis. Food Res. Int. 2013, 53, 780-785. [CrossRef]

36. Lu, X.; Zhao, Y.; Sun, Y.; Yang, S.; Yang, X. Characterisation of polysaccharides from green tea of Huangshan Maofeng with antioxidant and hepatoprotective effects. Food Chem. 2013, 141, 3415-3423. [CrossRef]

37. Yang, J.; Chen, B.; Gu, Y. Pharmacological evaluation of tea polysaccharides with antioxidant activity in gastric cancer mice. Carbohydr. Polym. 2012, 90, 943-947. [CrossRef]

38. Yang, L.; Fu, S.; Zhu, X.; Zhang, L.-M.; Yang, Y.; Yang, X.; Liu, H. Hyperbranched acidic polysaccharide from green tea. Biomacromolecules 2010, 11, 3395-3405. [CrossRef]

39. Chen, X.; Lin, Z.; Ye, Y.; Zhang, R.; Yin, J.; Jiang, Y.; Wan, H. Suppression of diabetes in non-obese diabetic (NOD) mice by oral administration of water-soluble and alkali-soluble polysaccharide conjugates prepared from green tea. Carbohydr. Polym. 2010, 82, 28-33. [CrossRef]

40. Wang, D.; Zhou, X.; Li, L.; Hou, Y.; Sun, J.; Wang, J. A rapid quantitative method for polysaccharides in green tea and oolong tea. Eur. Food Res. Technol. 2008, 226, 691-696. [CrossRef]

41. Zhou, X.; Wang, D.; Sun, P.; Bucheli, P.; Li, L.; Hou, Y.; Wang, J. Effects of soluble tea polysaccharides on hyperglycemia in alloxan-diabetic mice. J. Agric. Food. Chem. 2007, 55, 5523-5528. [CrossRef] [PubMed]

42. Wang, D.; Wang, C.; Li, J.; Zhao, G. Components and activity of polysaccharides from coarse tea. J. Agric. Food. Chem. 2001, 49, 507-510. [CrossRef]

43. Zhang, X.; Chen, H.; Zhang, N.; Chen, S.; Tian, J.; Zhang, Y.; Wang, Z. Extrusion treatment for improved physicochemical and antioxidant properties of high-molecular weight polysaccharides isolated from coarse tea. Food Res. Int. 2013, 53, 726-731. [CrossRef]

44. Wang, Y.; Liu, Y.; Huo, J.; Zhao, T.; Ren, J.; Wei, X. Effect of different drying methods on chemical composition and bioactivity of tea polysaccharides. Int. J. Biol. Macromol. 2013, 62, 714-719. [CrossRef]

45. Wang, Y.; Yang, Z.; Wei, X. Sugar compositions, $\alpha$-glucosidase inhibitory and amylase inhibitory activities of polysaccharides from leaves and flowers of Camellia sinensis obtained by different extraction methods. Int. J. Biol. Macromol. 2010, 47, 534-539. [CrossRef]

46. Jin, F.; Jia, L.-Y.; Tu, Y.-Y. Structural analysis of an acidic polysaccharide isolated from white tea. Food Sci. Biotechnol. 2015, 24, 1623-1628. [CrossRef]

47. Xu, R.; Ye, H.; Sun, Y.; Tu, Y.; Zeng, X. Preparation, preliminary characterization, antioxidant, hepatoprotective and antitumor activities of polysaccharides from the flower of tea plant (Camellia sinensis). Food Chem. Toxicol. 2012, 50, 2473-2480. [CrossRef] [PubMed]

48. Wang, Y.; Yu, L.; Zhang, J.; Xiao, J.; Wei, X. Study on the purification and characterization of a polysaccharide conjugate from tea flowers. Int. J. Biol. Macromol. 2010, 47, 266-270. [CrossRef] [PubMed]

49. Wang, Y.; Liu, Y.; Mao, F.; Liu, Y.; Wei, X. Purification, characterization and biological activities in vitro of polysaccharides extracted from tea seeds. Int. J. Biol. Macromol. 2013, 62, 508-513. [CrossRef] [PubMed]

50. Wang, Y.; Shao, S.; Xu, P.; Chen, H.; Lin-Shiau, S.-Y.; Deng, Y.-T.; Lin, J.-K. Fermentation process enhanced production and bioactivities of oolong tea polysaccharides. Food Res. Int. 2012, 46, 158-166. [CrossRef]

51. Mao, Y.; Wei, B.; Teng, J.; Xia, N.; Zhao, M.; Huang, L.; Ye, Y. Polysaccharides from Chinese Liupao dark tea and their protective effect against hyperlipidemia. Int. J. Food Sci. Tech. 2018, 53, 599-607. [CrossRef]

52. Xu, P.; Chen, H.; Wang, Y.; Hochstetter, D.; Zhou, T.; Wang, Y. Oral administration of puerh tea polysaccharides lowers blood glucose levels and enhances antioxidant status in alloxan-induced diabetic mice. J. Food Sci. 2012, 77, H246-H252. [CrossRef] [PubMed] 
53. Wang, M.; Chen, G.; Chen, D.; Ye, H.; Sun, Y.; Zeng, X.; Liu, Z. Purified fraction of polysaccharides from Fuzhuan brick tea modulates the composition and metabolism of gut microbiota in anaerobic fermentation in vitro. Int. J. Biol. Macromol. 2019, 140, 858-870. [CrossRef]

54. Scoparo, C.T.; Souza, L.M.; Dartora, N.; Sassaki, G.L.; Santana-Filho, A.P.; Werner, M.F.P.; Borato, D.G.; Baggio, C.H.; Iacomini, M. Chemical characterization of heteropolysaccharides from green and black teas (Camellia sinensis) and their anti-ulcer effect. Int. J. Biol. Macromol. 2016, 86, 772-781. [CrossRef] [PubMed]

55. Wang, Y.; Wei, X.; Jin, Z. Structure analysis of a neutral polysaccharide isolated from green tea. Food Res. Int. 2009, 42, 739-745. [CrossRef]

56. Wei, X.; Chen, M.; Xiao, J.; Liu, Y.; Yu, L.; Zhang, H.; Wang, Y. Composition and bioactivity of tea flower polysaccharides obtained by different methods. Carbohydr. Polym. 2010, 79, 418-422. [CrossRef]

57. Chen, D.; Chen, G.; Chen, C.; Zeng, X.; Ye, H. Prebiotics effects in vitro of polysaccharides from tea flowers on gut microbiota of healthy persons and patients with inflammatory bowel disease. Int. J. Biol. Macromol. 2020, 158, 968-976. [CrossRef]

58. Chen, X.; Han, Y.; Meng, H.; Li, W.; Li, Q.; Luo, Y.; Wang, C.; Xie, J.; Wu, L.; Zhang, X.; et al. Characteristics of the emulsion stabilized by polysaccharide conjugates alkali-extracted from green tea residue and its protective effect on catechins. Ind. Crops Prod. 2019, 140, 111611. [CrossRef]

59. Li, Q.; Shi, J.; Du, X.; McClements, D.J.; Chen, X.; Duan, M.; Liu, L.; Li, J.; Shao, Y.; Cheng, Y. Polysaccharide conjugates from Chin brick tea (Camellia sinensis) improve the physicochemical stability and bioaccessibility of $\beta$-carotene in oil-in-water nanoemulsions. Food Chem. 2021, 357, 129714. [CrossRef]

60. Xiang, L.; Si, C.; Zhao, Z.-T.; Meng, Z.; Yi, H.; Ye, X.-M.; Qi, A.; Ouyang, K.-H.; Wang, W.-J. Effects of polysaccharides from Yingshan Yunwu tea on meat quality, immune status and intestinal microflora in chickens. Int. J. Biol. Macromol. 2020, 155, 61-70. [CrossRef]

61. Li, S.; Wang, X.; Li, W.; Yuan, G.; Pan, Y.; Chen, H. Preparation and characterization of a novel conformed bipolymer paclitaxelnanoparticle using tea polysaccharides and zein. Carbohydr. Polym. 2016, 146, 52-57. [CrossRef]

62. Wu, S.; Li, N.; Yang, C.; Yan, L.; Liang, X.; Ren, M.; Yang, L. Synthesis of cationic branched tea polysaccharide derivatives for targeted delivery of siRNA to hepatocytes. Int. J. Biol. Macromol. 2018, 118, 808-815. [CrossRef] [PubMed] 